\title{
Prevention of Atopy-Current Concepts and Personal Experience
}

\section{Luisa Businco and Arnaldo Cantani}

Recent advances in knowledge of the innate mechanisms of mucosal immunity and their potential role in mucosal infections, food allergies, and other disorders that may be immunologically mediated have important implications for the development of rational therapeutic strategies. In addition, it is increasingly apparent that the mucosal immune system has powerful regulatory mechanisms that allow it to react selectively to substances found in the mucosal environment. ${ }^{1}$

This chapter reviews our understanding of the immunological mechanisms concerned with the mucosal immune system, especially as they apply to preventive measures. We also shall discuss the results of our recent studies.

\section{Mucosal Immune System}

The prominence of IgA in mucosal secretions and its abundance in adjacent tissues suggest its crucial role in local resistance. Secretory $\operatorname{Ig}$ A (sIgA), which may be considered the hallmark of the mucosal immune system, is largely derived from IgA precursor B lymphocytes found in abundance in gut-associated lymphoid tissue (GALT) and in bronchus-associated lymphoid tissue (BALT). ${ }^{2}$ The major sources of these cells are Peyer's patches and bronchial lymphoid tissue.

It has been shown that IgA-bearing cells generated in GALT travel by lymphatics to mesenteric lymph nodes $(\mathrm{MN})$ where they divide and differentiate. From the MN, cells proceed via the thoracic duct to the blood, when they appear to home selectively to the lamina propria of various mucosal surfaces, principally in the intestine, to become IgA plasma cells. ${ }^{3}$ However, it is not yet clear whether repeated antigen stimulation or particular $\mathrm{T}$ cells (or both) play the predominant role in driving B cells to become IgA producers. ${ }^{4,5}$

This work was supported by a grant from Ministero della Pubblica Istruzione and Fondazione Cenci-Bolognetti, Roma.

From the Division of Allergy and Clinical Immunology, 1st Department of Pediatrics, Università di Roma La Sapienza, Viale Regina Elena, Roma, Italy.

Send correspondence and requests for reprints to Luisa Businco, Division of Allergology and Clinical Immunology, 1st Department of Pediatrics, Università di Roma, La Sapienza, Viale Regina Elena, 324 00161, Rome, Italy. 
The gastrointestinal tract has a unique role in relation to food allergic diseases. The development of mucosal immune responses to dietary as well as to microbial and other environmental antigens represents a first line of defense against the penetration of these antigens. It is generally agreed that the intestinal mucosa is immature in the newborn period at a time when it is exposed to a wealth of macromolecular antigens. ${ }^{6}$ It also has been shown that large molecules can reach the circulation via persorption, thus coming into contact with other parts of the body where nonspecific damage might occur, ${ }^{7}$ especially in at-risk infants.

The majority of gut lymphocytes are $\mathrm{T}$ cells and, like all $\mathrm{T}$ cells, derive from precursors that are in the thymus. ${ }^{8}$ More immediate precursor cells are stimulated by antigens in the lymphoid tissue, such as the Peyer's patches. Their cycle is analogous to the differentiation pathway of the precursors of intestinal IgA-producing plasma cells from B cells, which are also stimulated in the Peyer's patches. The functional properties of the gut $T$ cells have been extensively studied. ${ }^{9-11}$ The terminal maturation of $B$ cells is controlled in a positive fashion by helper $\mathrm{T}$ cells and macrophages that present not only antigens but also many polyclonal activators, including pokeweed mitogen, to B cells. A separate network of $T$ cells, called suppressor $T$ cells, regulates the maturation of $B$ cells in a negative fashion. As the precursors of suppressor $T$ cells emerge from the thymus, they are activated into the final effectors of suppression by interaction with antigens or mitogens as well as with inducer or activator cells. ${ }^{5,8,12}$ Helper and suppressor T-cell subsets are not static but remain in a state of dynamic balance via a number of complex circuits. ${ }^{13}$ The helper T-cell subset provides help for B cells and at the same time induces a set of suppressor $T$ cells. The suppressor $T$ cells in turn inhibit the antibody response. This process has been called feedback suppression. ${ }^{14}$

In both animals and humans, the majority of intraepithelial $\mathrm{T}$ cells have a suppressor/cytotoxic phenotype rather than a helper-inducer one. In contrast, human lamina propria $\mathrm{T}$ cells have mainly a helper/inducer phenotype. ${ }^{15}$ It may take years to analyze how this complex environment affects the cellular interactions and regulatory events that determine the immune response in GALT.

\section{Recent Advances in Mucosal Immunoregulatory Mechanisms}

Of the immunoregulatory mechanisms characteristic of the mucosal immune system, the best known involves the formation of suppressor $\mathrm{T}$ cells after oral administration of antigens. ${ }^{16}$ An important feature of this suppressor cell response is that it may be immunoglobulin class-specific. Consequently, the suppression may affect largely IgM or IgG responses rather than IgA responses. Evidently a dual activation of helper cells for the IgA system and suppressor cells for IgM and IgG synthesis occurs. ${ }^{16}$

In studies analyzing the regulation of mitogen-induced Ig synthesis, it was found that cloned $T$ cells act as switch cells that induce IgM B cells (and only these cells) to differentiate into $\operatorname{IgA} B$ cells. Furthermore, cells bearing $\operatorname{IgA}$, but not cells secreting $\operatorname{IgA}$, are produced under the influence of the $\operatorname{IgA}$ switch 
T cells. Additional and different helper cells are necessary for terminal differentiation into IgA secreting cells. ${ }^{17}$

A second mechanism of mucosal immunoregulation may involve nonspecific induction of suppressor $T$ cells. In particular, it has been shown that bacterial endotoxin or lipopolysaccharide (LPS) in the gastrointestinal lumen can induce a nonspecific suppression of mucosal immune responses. ${ }^{18}$ It has been proposed that in the normal gastrointestinal tract, LPS either induces suppressor cells directly, or it induces activation of cells, eg, B cells and macrophages, which in turn induce feedback suppressor T cells. ${ }^{18}$ The exact significance of these observations and their relation to the phenomenon of oral tolerance is speculative at present.

\section{Physiological Uptake of Macromolecules}

The initial events in the process of macromolecular transport in the small intestine appear to be the adsorption and subsequent endocytosis of antigens by the microvillous membrane. Soluble proteins interacting with the surface of the gut stimulate the invagination of that surface to form small vesicles. After invagination, macromolecules are transported within larger, membranebound phagosomes. Intracellular digestion occurs when lysosomes combine to form phagolysosomes. However, some macromolecules may bypass this digestive process to be released into the intercellular space by an exocytotic process and to be taken up into the circulation. Alternatively, macromolecules may cross the tight-junction barrier between cells and diffuse into the intercellular space. ${ }^{19}$ Under normal conditions, macrophages and plasma cells present in the lamina propria of the small intestine or Kupffer's cells in the liver (fixed reticuloendothelial cells) located adjacent to the portal circulation interact with absorbed antigens acting as a secondary line of defense against the penetration of antigens into the circulation. ${ }^{20}$ Normally, the transport of molecules results in no ill effects because of these defense mechanisms. However, when excessive quantities of antigens enter the body because of interferences with intracellular capacity to digest them, or when secondary defenses are lacking or diminished, antigens may enter the circulation and contribute to clinical disease ${ }^{6}$ as will be discussed later.

Recently, a specialized epithelial cell known as a membranous or microfold (M) epithelial cell, has been described overlying GALT in the ileum of several species, including humans. ${ }^{7,21}$ It has been speculated that the $M$ cell, which has few short microvilli and no lysosomes to digest antigens that pass through, ${ }^{21}$ may be the route whereby intestinal antigens are transported to the tissue $B$ and T lymphocytes ${ }^{15}$ that are present in the dome epithelium of Peyer's patches. ${ }^{9}$ There antigen recognition occurs. The sensitized $B$ cells then move to the regional lymph nodes, undergo maturation and ultimately seed along the mucus epithelium of many tissues, including mammary glands. ${ }^{4}$

However, a crucial role of the $M$ cell as the access route for induction of intestinal mucosal immune and hypersensitivity reactions has not been confirmed. In particular, neither food proteins nor other environmental antigens have been actually shown to use the $M$ cell as the route of access to the lymphoid tissue. ${ }^{7}$ 


\section{Factors Modulating Antigen Uptake}

\section{Immunological Factors}

Current concepts of the mucosal immune system not only suggest that IgA is the principal immunoglobulin produced locally in the wall of the intestine but also that there is a specialized mucosal immunoregulation mechanism acting via secretory IgA. Intestinal antibodies capable of inhibiting bacterial adherence may represent an important advantage in establishing an indigenous gut bacterial flora. In addition, secretory IgA that complexes with cholera toxin can prevent toxin from binding to receptors on intestinal microvillus membranes and thus interfere with the active secretion associated with toxigenic diarrhea. ${ }^{20}$

Intestinal antigens also become rapidly associated with antibodies present in the glycocalyx; immune complex formation prevents migration of antigen to the cellular membrane surface and interferes with pinocytosis by enterocytes. Moreover, immunocomplex formation within the intestinal lumen may trigger the release of goblet-cell mucus, which can interfere with further antigen penetration across the mucosal barrier. ${ }^{22}$

\section{Nonimmunological Factors}

While immune responses constitute a specific mucosal defense system, a heterogeneous group of nonimmunologic factors are said to participate in protecting the gastrointestinal barrier. Taken individually, they are incapable of mounting a controlled response, whereas their combined action contributes to the overall protection of the gut mucosa. An outline of these factors will follow.

For many decades, the importance of mucus in intestinal immunity has been known. Before bacteria can become a problem, mucus secreted by the goblet cells engulfs viable organisms, thus accelerating their elimination. Moreover, it appears that peristalsis, aided by mucus secretion, can result in removal of most foreign bodies that enter the small intestine. ${ }^{23} \mathrm{~A}$ rise in intestinal goblet cells numbers in primary Nippostrongylus brasiliensis infections has been demonstrated..$^{24}$ Other evidence suggests that the goblet cell mucous coat covering the epithelial surface of the gastrointestinal tract may represent an important protective barrier against the penetration of microorganisms, toxins, and antigens present in the external environment of the lumen. ${ }^{23}$ In addition, gastric mucus has been demonstrated to reduce the binding of toxins to epithelial cell receptors. ${ }^{25}$ However, it is known that factors such as hormones, aging, and malnutrition can affect the molecular structure of the mucins produced. How this is achieved or the consequences of mucin structural differences has not been so far elucidated.

In addition to goblet-cell mucus, a number of other nonimmunological factors are required to adequately control macromolecular digestion and absorption at the mucosal surface.

Recent studies indicate that the glycocalyx is an active metabolic compartment that aids in the control of bacterial adherence to epithelial surfaces and interferes with attachment and uptake of antigens and enterotoxins. ${ }^{26}$ In the neonatal stomach, low levels of gastric acid and pepsin limit gastric proteo- 
lysis, while the water in secretions acts as a diluent, thus reducing the concentration of antigen. ${ }^{27}$

Peristaltic movements ensure that antigens, indigenous flora, and intestinal mucus are rapidly mixed, thus constituting an additional factor in controlling proliferation of bacteria within the small intestine. Impaired peristalsis, on the other hand, allows bacterial overgrowth. Peristalsis also decreases adherence of macromolecules and their engulfment by enterocytes. ${ }^{28}$ Moreover, pancreatic enzymes adsorbed to the surface of the small intestine enhance the breakdown of antigen-antibody complexes within the glycocalyx compartment of the gastrointestinal surface, thereby diminishing the antigens available for persorption by intestinal epithelial cells. ${ }^{23}$

As already mentioned, reticuloendothelial cells of the liver phagocytize the noxious substances that may enter the portal circulation. The Kupffer's cells may act as a filter to deter transport into the systemic circulation. Furthermore, normal bacterial flora is promoted by lysozyme, bile salts, and specific antibodies. The normal flora protects the host by competitively inhibiting colonization with potentially harmful organisms. ${ }^{22}$ In conclusion, decreased adherence as well as increased breakdown of macromolecules result in less availability of these antigens for adsorption to the microvillus surface and uptake via the mucosa.

\section{Factors Enhancing Antigen Uptake}

The risk of developing allergic symptoms to foods is due in part, at least, to enhanced absorption of macromolecules as a result of increased permeability of the gut during the first weeks of extrauterine life. ${ }^{29,30}$ Passage of small amounts of these molecules induces little ill effect in most healthy adults. ${ }^{20}$ Under normal circumstances, sIgA constitutes the first line of defense against ingress of foreign protein at the mucosal level. ${ }^{31}$ It must be remembered, however, that sIgA is virtually undetectable at birth, possibly due to the almost nonexistent antigenic sensitization in utero. By four weeks of age, however, $92 \%$ of infants have been found to have increasing amounts of salivary $\operatorname{Ig} A$ levels. ${ }^{32}$ Recent studies have demonstrated that slgA antibody levels remain relatively low only during the first six months of life.$^{33}$ In contrast, serum IgA levels increase more slowly and peak adult levels are not attained until about 10-12 years of age. ${ }^{34}$ Thus there is a transient immunological gap during childhood, which is possibly related to enhanced macromolecular transport.

Patients with selective IgA deficiency who lack $\operatorname{sg} A$ and have very low levels of serum IgA are more easily exposed to the antigenic stimulus of food proteins that may penetrate the mucosa and lead to specific antibody formation. ${ }^{35}$ It has been reported ${ }^{36}$ that $59 \%$ of patients with selective IgA deficiency have circulating immune complexes, $50 \%$ have milk precipitins, $23 \%$ have precipitins to bovine serum, and $13 \%$ have precipitins to fetal calf serum. These patients also have an increased frequency of allergic disease. ${ }^{37}$ Selective IgA deficiency is the most common form of primary immunodeficiency, as is evident in Table $1 .^{37}$

Finally, other conditions can predispose to an enhanced permeability of macromolecules within the gastrointestinal tract. These include local antibody deficiency and disruption of nonspecific defense mechanisms. ${ }^{20}$ 
Table 1. Number and Percentage of Cases of Primary Immunodeficiency Registered until April 1982, in Italian Register for Immunodeficiency

\begin{tabular}{lcc} 
& No. of & \\
\multicolumn{1}{c}{ Diagnosis } & patients & Percentage \\
\hline SCID & 45 & 5.64 \\
PNP-deficiency & 2 & 0.25 \\
DiGeorge syndrome & 8 & 1.00 \\
T-lymphocyte defects & 58 & 7.27 \\
X-linked agammaglobulinemia & 33 & 4.14 \\
Common variable hypogammaglobulinemia & 117 & 14.68 \\
IgA defect & 354 & 44.40 \\
Selective IgG and/or IgM defect & 22 & 2.76 \\
Hypogammaglobulinemia with hyper IgM & 5 & 0.62 \\
Immunodeficiency and short limbed dwarfism & 6 & 0.75 \\
Ataxia telangiectasia & 50 & 6.27 \\
Wiskott-Aldrich syndrome & 14 & 1.75 \\
Hyper IgE syndrome & 12 & 1.50 \\
Chronic granulomatous disease & 12 & 1.50 \\
Complement defects & 13 & 1.63 \\
Phagocyte disorders (phagocytosis & 27 & 3.38 \\
chemotaxis, killing defect) & & \\
Chronic mucocutaneous candidiasis & 19 & 2.38 \\
Registered cases & 797 & \\
\hline
\end{tabular}

We shall now discuss the influence of antenatal and postnatal factors that might affect sensitization to allergens and subsequent allergies. In many instances, these predisposing factors can be identified, thus revealing the cause or the mechanism of atopy, besides suggesting a means for its prevention.

\section{Predisposing Factors}

\section{Genetic Factors}

Current information suggests that genetic factors play a paramount role in the development of atopy. It has been known for centuries that children with a parental history of atopic disease are at a high risk for the development of atopic symptoms at an earlier age. It has been found that if one parent is affected, the chances of an offspring being affected approach $50 \%$, and if both parents are affected, this figure increases to $66 \%$. This compares to a much smaller proportion of affected children born of parents with no atopic disease. ${ }^{39}$ Recent prospective studies have demonstrated that exclusive, prolonged breastfeeding during the newborn period and early infancy exerts a prophylactic effect on the development of atopic diseases in children at risk according to family history. In these children, atopic disease also may be postponed or its course may be less severe. ${ }^{40}$

\section{Environmental Factors}

In addition to genetic controls, different environmental factors seem to play a role in promoting allergic sensitization and the subsequent development of atopy. A review of these factors will follow. 
Time of Birth. It has recently been suggested that the type of atopic sensitization, which may also manifest itself during later life, is dependent on the month of birth. In 1976 , Soothill et $\mathrm{al}^{41}$ found that the exposure to particular antigens during the neonatal period was strongly associated with the subsequent development of allergy. They found evidence of an increased incidence of children with positive skin tests to Dermatophagoides pteronyssinus among those born in September and October. In Great Britain, the maximal risk of sensitization to Dermatoph. is associated with this particular birth season.

Several studies have analyzed the dependence of the sensitization on the month of birth. These studies have demonstrated a significantly higher incidence of sensitization to pollens in children born in March-May, and to mites in children born in September-October. ${ }^{42-44}$ Early in life, there may be a physiological deficit in the mechanisms acting to the exclusion and elimination of antigens ${ }^{6}$ that, in connection with the season and place of birth, may represent a transient period of vulnerability to adverse environmental factors, predisposing to the atopic sensitization. Moreover, a high incidence of atopic diseases has been evidenced in immunodeficient patients. ${ }^{45}$ Taken together these observations suggest that transient immunodeficiency may underlie much childhood allergy. In this regard, Juto et $\mathrm{al}^{46}$ have recently reported that in a group of babies with a short duration of breastfeeding and early weaning to cow's milk, an altered T-cell function was detectable before the onset of allergic manifestations. These studies indicate that atopic disease is associated with imbalances between subpopulations of $\mathrm{T}$ cells. ${ }^{47}$

The implication of these observations is that exposure to allergens in early extrauterine life when the infant is known to be particularly vulnerable to penetration by harmful intraluminal substances ${ }^{6,41,48}$ is accompanied by a high probability of sensitization and the subsequent development of atopic disease.

Prenatal Factors. Several studies suggest that infections and maternal food or drug intake may be important determinants of risk for developing atopic allergy. It has been recently reported that $\operatorname{IgE}$ concentrations were high in cord blood if the pregnant mothers had been administered progesterone. However, these elevated levels were not associated with an increased development of atopic diseases in the infants born to these mothers. ${ }^{49}$ Newborn IgM levels also were not related to subsequent allergies. ${ }^{49}$

Can a child come into the world with atopy? Although the research in this field is scarce, some experimental and clinical observations indicate that an intrauterine sensitization is possible.

As early as 1928, Ratner demonstrated intrauterine sensitization to cow's milk proteins in guinea pigs and speculated on analogous sensitization in humans. ${ }^{50}$ Many years later, it was found that synthesis of IgE in utero occurs as early as the 11 th week of gestation. ${ }^{51}$ In addition, it was also demonstrated that the fetus is capable of producing specific IgE antibodies to food allergens that were ingested by the mother during pregnancy. Actually, antibodies to cow's milk and soybean proteins have been detected in both the amniotic fluid and cord blood. ${ }^{52-54}$ Because the mothers were RAST-negative to these allergens, it follows that the antibodies had been synthetized by the fetus. Several investigators have observed that sensitization in utero is a distinct 
possibility. Therefore, they recommend that atopic women not ingest excessive amounts of potentially allergenic foods such as egg and cow's milk during pregnancy. ${ }^{55-60}$

Pediatricians sometimes observe anaphylactic reactions occurring after an infant's first exposure to a food allergen. ${ }^{54,55,61}$ Such reactions are now attributed to intrauterine sensitization.

In conclusion, experimental and clinical data suggest that infants can be born with atopy. However, further studies are needed to clarify the mechanisms of antenatal sensitization, and especially which food antigens are most likely to cross the placental barrier and whether the controlled ingestion of these foods by the mother during pregnancy can prevent or minimize sensitization of the fetus.

Cigarette Smoking. Among the environmental factors favoring the development of atopic disease, cigarette smoke plays a major role. Evidence is accumulating that there is a connection between parental smoking habits and atopic disease in children.

Recently, it has been observed that atopic symptoms begin earlier in children of parents who smoke. ${ }^{62}$ Moreover, immunologic studies corroborate these findings. Reports of higher IgE levels in adult smokers ${ }^{63}$ and in infants of smoking atopic parents ${ }^{64}$ support the view that immunologic abnormalities may be relevant, although they may be effects rather than causes. The issue of whether smoking acts largely by irritating the respiratory mucosa, ${ }^{65}$ facilitating both the penetration of antigens and the spread of infection, or by a direct action on the immune system has yet to be resolved. All current results suggest the importance of environmental controls. Thus there are grounds to forbid smoking not only in an allergic child's home but also in the house of children at risk for the development of allergic disease. In addition, parents should not expose their children to smoke in other confined spaces, such as the family car. Not only is tobacco smoke an irritant, but it may lead to an increased susceptibility to respiratory viral infections. ${ }^{66}$ Another recent report indicates that adult smokers contract influenza with undue frequency. ${ }^{67}$

The rates of influenza also are elevated in smokers' children. ${ }^{67,68}$ Because these infections often induce asthma, a vicious circle may be initiated, especially in winter months when virus transmission is facilitated: parents' smoking $\rightarrow$ viral respiratory infections $\rightarrow$ asthma in the child. Perhaps only a vigorous prohibition of smoking can interrupt this circle.

Environmental Factors. As mentioned earlier, the infant's environment during the first six months of life has the potential of provoking allergic sensitization. Children living in rural districts may have increased pollen and animal contacts, and thus may manifest atopic symptoms at an earlier age. ${ }^{62}$

The importance of environmental control has recently been reevaluated. It has been demonstrated that avoidance of provoking antigens in infancy can not only lead to freedom from allergic disease but also can reduce bronchial hyperreactivity present in asthmatic patients. ${ }^{69} \mathrm{We}$ interpret these observations as having great practical relevance. Specific hyperreactivity represents the Achilles' heel of asthmatic children. In the light of evidence showing that 
bronchial hyperreactivity is ameliorated when environmental allergenicity is reduced, it is possible to consider that bronchial hyperreactivity may be secondary to allergy, at least in children. It has been suggested that repeated bronchospasm might damage bronchial muscles and nerves, thus leading to nonspecific hyperreactivity. It also has been postulated that release of mediators from mast cells in response to an IgE-mediated mechanism might contribute to the development of bronchial hyperreactivity. ${ }^{70}$

Infections. Viral infections frequently trigger asthmatic attacks in children. In the last few years, many studies have reported that infection with several viruses, including respiratory syncytial virus (RSV), parainfluenza (types 1-3), coronavirus, adenovirus, and cytomegalovirus may contribute to the development of allergic sensitization. In children of atopic parents, allergic sensitization accompanied by $\operatorname{IgE}$ synthesis began after viral upper respiratory infections, in concert with specific antibody responses to the virus. ${ }^{53}$ Increased levels of IgE have been shown in various viral infections. ${ }^{71,72}$ Recently, RSVspecific IgE antibodies have been found to be persistently present in patients affected by RSV infections. ${ }^{73} \mathrm{~A}$ subsequent study from these investigators ${ }^{74}$ demonstrated the association of high RSV-IgE titers and concentrations of histamine in the nasopharyngeal secretions of patients with wheezing caused by RSV infection. The authors suggest that the disease may be due to hyperproduction of RSV-IgE, which results in an enhanced release of histamine and other chemical mediators causing airway obstruction.

There are several mechanisms by which viral infections could stimulate IgE synthesis and thereby favor the development of an atopic disease. They could depress T-suppressor cells, which in turn allow increased IgE synthesis. In addition, their cytopathic effect on respiratory mucosal membranes might favor antigen penetration. Viruses might also accentuate the $\beta$-adrenergic blockade, thus enhancing IgE synthesis. ${ }^{75}$ Moreover, RSV-induced lymphocyte production ${ }^{76}$ might produce soluble factors that are chemotactic for basophils ${ }^{77}$ and enhance antigen-induced histamine release from basophils. ${ }^{78}$

In conclusion, the studies so far reviewed afford an insight into the association between viral infections and IgE synthesis. In particular, these studies explain in part why RSV bronchiolitis in infancy is followed by asthma in about $50 \%$ of cases. . $^{79}, 80$

Early Weaning. Early weaning seems to be of importance in subsequent sensitization to allergens. Several prospective studies done in different countries have demonstrated that early weaning is associated with an increased risk of atopic disease. On the other hand, prolonged breastfeeding exerts a prophylactic effect on the development of allergies, at least during the first years of life ${ }^{40}$ It may be argued that infants are at risk of developing atopy especially during the first weeks of life. This is shown by experimental and clinical studies that have demonstrated that macromolecules can cross the intestinal mucosa at any age, the absorption being greatest in early life. ${ }^{29,30}$ Rothberg ${ }^{30}$ reported that the absorption of bovine serum albumin in premature infants was higher than in older children. Eastham et $\mathrm{al}^{48}$ were able to show that food protein macromolecules are absorbed more readily into the circu- 
lation during the first three months of life than later. It is apparent from the foregoing that the neonatal intestine may absorb greater quantities of ingested protein antigens than the mature adult intestine, which suggests that the mucosal defense system that promotes exclusion and elimination of the antigens is immature. Morphological studies done on fetal intestinal cells of the monkey and of humans showed excessive uptake of large molecules by intestinal epithelial cells. The morphological features of these cells suggested a structural immaturity ${ }^{81,82}$ This structural and functional immaturity can persist beyond fetal life into the neonatal period where new exposures come from without in the form of bacterial and food antigens.

During the early neonatal period, the human gastrointestinal mucosa develops in both structure and function, forming a defense system that is operational against the penetration of antigenic material in the intestinal lumen (bacteria, toxins, and antigens). However, due to the immunological gapthe transient lack of $\operatorname{sIgA}$-and the functional immaturity of the intestinal tract, the mucosal barrier remains immature for varying periods of extrauterine existence and therefore protects the neonate incompletely. ${ }^{6}$ Indeed one is struck by the relative ease with which the intestinal barrier can be penetrated, especially by bacteria. A vicious cycle of mucosal damage, increased antigen absorption, and atopic sensitization may thus be initiated. ${ }^{23}$

It is puzzling that the normal neonate lacks slgA antibody activity during the first two weeks of life, when such immunity is of the utmost importance in dealing with a wealth of microbial, dietary, and other environmental agents. Nevertheless, while the machinery for mucosal immunity is developing, the ingestion of colostral and breast milk IgA affords protection. ${ }^{27.83-85}$ The implications of these observations for the intestinal host defenses are obvious.

We want to stress that early supplements of cow's milk are often given in maternity hospitals without the mother's awareness. This is an unwise practice because supplementary feeds may be as sensitizing as full bottle feedings ${ }^{86}$ Experiments with an animal model have demonstrated that small quantities of oral antigens are more harmful than larger ones. ${ }^{87}$ An elegant study by Roberts and Soothill ${ }^{88}$ recently demonstrated that the postweaning $\operatorname{IgE}$ and IgG antiovalbumin antibody responses were greater in rat pups that had received a cow's milk-based supplementary feed than in litter mates that had not. Furthermore, they showed that the intestinal absorption of $\beta$-lactoglobulin was enhanced by the presence of ovalbumin in rats that had IgE antiovalbumin. ${ }^{88}$ These data can be explained by the fact that reaginic antibody provokes an immediate hypersensitivity reaction in the gastrointestinal $\mathrm{mu}-$ cosa, thereby increasing gut permeability to $\beta$-lactoglobulin. ${ }^{89}$ These results suggest that cow's milk supplements administered to rats may contribute in a nonspecific way to the atopic sensitization to other allergens. Sensitization to an allergen thus may favor the absorption of other macromolecules, increasing the risk of allergy. Finally, it is likely that similar mechanisms are operative in the human newborn.

\section{Prevention by Dietary Manipulations}

Dietary management based principally on exclusive breastfeeding and/or soy formulas in the first months of life to prevent allergy have provided encour- 
aging results. Several prospective studies have confirmed this, ${ }^{38,50,90-93}$ whereas several retrospective studies yielded contradictory results. ${ }^{94-98}$

In particular, all prospective studies reported an improvement in atopic disease rates using breast milk ${ }^{90-92}$ or soy milk. ${ }^{38}$ In addition, two retrospective studies reported an improvement in eczema ${ }^{94}$ or asthma. ${ }^{96}$ The remaining three studies observed no differences either using breast or cow's milk ${ }^{97,98}$ or a combination of breast, soy, and cow's milk. ${ }^{95}$

In a recent prospective study, ${ }^{40}$ we evaluated the prophylactic effect of prolonged breastfeeding on the development of allergic disease in 101 newborns of atopic parents. Thirty-four newborns were exclusively breastfed during the first six months of life, 26 received soy milk supplements with breastfeeding for an average of 1.5 months, and 41 were fed cow's milk from birth. The study design also included a strict dietary avoidance of cow's milk by the nursing mothers. In addition, in the breast- and soy-milk-fed infants, none were weaned to solid food for the first six months and only selected weanings were permitted up to nine months of age.

There were 6/34 breastfed, 6/26 soy milk fed, and 15/41 cow's milk fed infants who developed atopic disease during the two years of follow-up. Our prospective study confirms, therefore, that prolonged breastfeeding as well as breastfeeding supplemented with soy milk exert a protective effect on the development of atopic sensitization in newborns at hereditary risk for allergic disease. ${ }^{40}$

As mentioned earlier, three retrospective studies ${ }^{95,97,98}$ failed to confirm this effect. Indeed, retrospective studies may yield controversial results due to various factors. In our view, it may be impossible for mothers to recall early supplementary feeds and/or former illnesses of their babies. In addition, atopic disease may be difficult to diagnose in young infants, especially in retrospect.

Thus there are grounds to recommend preventive measures at birth and even during pregnancy. Fortunately, because it would be unethical to require a feeding method against the mother's will, nature has provided a unique food that protects the infant, ie, human milk. It is now increasingly apparent that there are sound indications that breastfeeding is better than other methods of infant feeding. Proteins in breast milk are homologous and the likelihood of infant sensitization is minimal. A wide variety of humoral and cellular elements contained in breast milk may contribute to protection against enteric infections and to intestinal integrity. ${ }^{83,90,97,99}$ Conversely, bacterial overgrowth has harmful effects on mucosal integrity, thereby enhancing the attachment of antigens to the intestinal epithelium. It has been demonstrated that breast milk protects against respiratory tract infections. ${ }^{90}$ Viral infections often stimulate IgE synthesis. ${ }^{71,72}$ There is an interesting study of infants at risk that shows the association between the development of allergenic sensitization and early infections. ${ }^{53}$ Furthermore, IgE bound to epithelial cells has been demonstrated in the respiratory tract of infants with RSV-induced bronchiolitis, ${ }^{73}$ a condition that is less frequent in breastfed infants. ${ }^{38}$ Breast milk contains substances called mucosal growth factors that stimulate early maturation of the intestine and gut closure. ${ }^{100}$ Closure of the intestine reduces the crucial period in which newborn infants are particularly vulnerable to infection and pathological absorption of macromolecules. The fecal flora of breastfed infants is characterized by a marked predominance of bifidobacteria 
and a constantly acid $\mathrm{pH}^{101}$ which further protect these infants from excess penetration of antigenic macromolecules. One study, however, has not confirmed this finding, suggesting there is no difference in the fecal flora of breast- and formula-fed babies. ${ }^{102}$ Finally, an immunoregulatory effect by breast milk cells has been reported. ${ }^{103}$ It was postulated that a soluble mediator(s) of immunologic regulation was released by human milk cells and that this factor(s) explained, in part, the peculiar immunologic behavior of human milk cells in vitro. The factor(s) was released in greater amounts by colostral cells than by cells in mature milk, and human colostrum was thought to play a role in activating local immunity in the gastrointestinal tract of the newborn.

Recently, the relationship between E-rosette forming cells (ERFC), lymphocyte responsiveness and atopic disease was studied prospectively in 70 healthy newborn infants. Of these, 40 had positive heredity for atopic disease and 30 did not. ${ }^{104}$ The study showed that heredity for atopic disease is commonly associated with low ERFC even before the infants develop any symptoms of allergy. The clinical relevance of these results was supported by the finding that in babies who received cow's milk based formulas serum $\operatorname{lgE}$ was significantly higher when there was a low ERFC count. These data could indicate that breastfeeding protects against allergy in infants at risk, namely those infants with positive heredity, and/or low ERFC counts, and/or high cord blood IgE. ${ }^{105}$ Thus low numbers of ERFC are commonly found in early infancy in babies with a positive heredity for allergy before they have developed any clinical symptoms of allergy. Moreover, cow's milk-fed infants with ERFC deficiency appear to develop higher IgE levels and allergy symptom scores than normal infants, possibly because they lack normal IgE-suppressive mechanisms. ${ }^{106}$

\section{Conclusions}

Prophylaxis against atopy/food allergy appears to be best achieved by breastfeeding for as long as the mother is able to do so. In particular, exclusive breastfeeding should be encouraged for as long as possible when there is a history of allergy in immediate members of the family.

We have stressed ${ }^{40}$ that when there is a high risk for allergy in offspring, the maternal diet during lactation should be modified to largely exclude potentially allergenic foods such as cow's milk. It also would be prudent to restrict the intake of cow's milk, egg, and perhaps other allergenic foods in the diet of pregnant women. We are continuing the follow-up of the 101 infants under study ${ }^{40}$ in order to ascertain whether the protective effect of breast milk will guarantee freedom from allergy and for how long.

Another problem must be considered in feeding breast milk to children at risk. Indeed, a mother may be unable to supply adequate amounts of her own milk even with the help of pumping and manual expression. A mother also may not like nursing her baby. Banked human milk has been considered as an alternative, but this is not feasible everywhere. Therefore, an infant requiring human milk may not receive optimal feeding as long as necessary. In this case, our advice is to feed the baby at risk with appropriate milk 
substitutes, among which soy milk appears to be a reasonable choice. ${ }^{107} \mathrm{How}$ ever, studies of soy-based formulas have yielded contradictory results. ${ }^{48,59,95}$ Nevertheless, 26 of the 101 newborns in our study received soy milk. ${ }^{40}$ It appears that the percentage of atopic disease in the soy-fed children is higher than in the breastfed group, but much less than in the cow's milk-fed infants (6/26 compared to $15 / 41$ in the latter group). Hence, soy formulas may be preferable to modified cow's milk formulas, provided care is taken to provide adequate nutrition. Other preparations including those containing predigested or hydrolyzed proteins should be evaluated.

As concerns some atopic diseases, to postpone their onset may lessen the severity of symptoms and even guarantee freedom from atopic disease. It is known that certain atopic diseases such as intractable diarrhea due to cow's milk protein allergy and atopic dermatitis are more frequent in young infants, in whom the clinical manifestations are also more severe than in older children. In like manner, asthma is a very serious disorder during the first years of life. It should be stressed that early in life, dietary manipulations can be successful only if cow's milk and other supplements are truly excluded from the diet, as any deviation can obscure the presence of a prophylactic effect from these measures. Even if parents are presented with serious psychological or financial difficulties, this must be weighed against potential therapeutic benefit of dietary management. In conclusion, we stress again that an ounce of prevention is worth a pound of cure.

\section{References}

1. Bienenstock J, Befus AD: Mucosal immunology. Immunology 41:249-270, 1980

2. Bienenstock J, McDermott $M$, Befus D: A common mucosal immune system. In Ogra PL, Dayton DH (eds): Immunology of Breast Milk. Raven Press, New York, pp 91-104, 1979

3. Roux ME, McWilliams M, Phillips-Quagliata JM, Weisz-Carrington P, Lamm ME: Origin of IGA-secreting plasma cells in the mammary gland. J Exp Med 146:1311-1322, 1977

4. Tomasi TB Jr, Larson L, Challacombe S, McNabb P: Mucosal immunity: the origin and migration of cells in the secretory system. Allergy Clin Immunol 65:12-19, 1980

5. Elson CO, Heck JA, Strober W: T-cell regulation of IgA synthesis, in Ogra PL, Dayton DH (eds): Immunology of Breast Milk. Raven Press, New York, pp 37-45, 1979

6. Businco L, Cantani A: Factors promoting atopy in childhood: Early diagnosis and prevention of allergic disorders. Immunol Clin Sper 1:177-186, 1982

7. Ferguson A: Pathogenesis and mechanisms in the gastrointestinal tract. Proceedings of the 1st Food Allergy Workshop. Medical Education Services Limited, Oxford, pp 28-38, 1980

8. Papiernik M, Bach JF: Post-natal development of T cells. 1. Study of the respective contribution of thymic cellular export, thymic humoral functions and $\mathrm{T}$ cell environment. J Immunol 123:2311-2315, 1979

9. Parrott DMV: The gut as a lymphoid organ. Clin Gastroenterol 5:211-218, 1976

10. Ferguson A: Progress report: intraepithelial lymphocytes of the small intestine. Gut 18:921-937, 1977

11. Husband AJ, Gowans JL: The origin and antigen-dependent distribution of IgA-containing cells in the intestine. J Exp Med 148:1148-1160, 1978

12. Papiernik M: Fonction thymique et maturation des lymphocytes. T Arch Fr Pédiatr 39:527-529, 1982

13. Cantor H, Gershon RK: Immunological circuits: cellular composition. Fed Proc 38:2058-2064, 1979 
14. Eardley DD, Hugenberger J, McVay-Boudreau L, Shen FW, Gershon RK, Cantor H: Immuno-regulatory circuits among T-cell sets. I. T-helper cells induce other T-cell sets to exert feedback inhibition. J Exp Med 147:1106-1115, 1978

15. Arnaud-Battandier F: Les phénomènes immunitaires locaux du tube digestif et leur pathologie chez l'enfant. Arch Fr Pédiatr 39:511-514, 1982

16. Strober $W$ : The regulation of mucosal immune system. J Allergy Clin Immunol 70:225-230, 1982

17. Kawanishi $H$, Saltzman LE, Strober $W$ : Characteristics and regulatory function of murine con-A induced, cloned $T$ cells obtained from Peyer's patches and spleen: mechanisms regulating isotype-specific immunoglobulin production by Peyer's patch B cells. J Immunol 129:475-483, 1982

18. McGhee JR, Kiyono H, Michalek SM, Babb JL, Rosenstreich DL, Mergenhagen SE: Lipopolysaccharide (LPS) regulation of the immune response: $T$ lymphocytes from normal mice suppress mitogenic and immunogenic responses to LPS. J Immunol 124:1603-1611, 1980

19. Walker WA, Isselbacher KJ: Uptake and transport of macromolecules by the intestine: possible role in clinical disorders. Gastroenterology 67:531-550, 1974

20. Walker WA: Antigen uptake in the gut: immunologic implications. Immunol Today 2:30-34, 1981

21. Owen RL: Sequential uptake of horseradish peroxidase by lymphoid follicle epithelium of peyer's patches in neonatal unobstructed mouse intestine: an ultrastructural study. Gastroenterology 72:440-451, 1977

22. Walker WA: Host defense mechanisms in the gastrointestinal tract. Pediatrics 57:901-906, 1976

23. Forstner GG, Forstner JF: Mucosal barrier and its defense mechanisms during the perinatal period, in Lebenthal E (ed): Testbook of Gastroenterology and Nutrition in Infancy. Raven Press, New York, pp 201-210, 1981

24. Miller HRP, Nawa Y: Immune regulation of intestinal goblet cell differentiation. Specific induction of nonspecific protection against helminths? Nouv Rév Fr Hématol 21:31-45, 1979

25. Strombeck DR, Harrold D: Binding of cholera toxin to mucin and inhibition by gastric mucin. Infect Immun 10:1266-1272, 1974

26. Walker WA, Isselbacher KJ: Intestinal antibodies. N Engl J Med 297:767-773, 1977

27. Lebenthal E, Freier S, Lee PC: Ontogeny of the G.I. tract and food hypersensitivity, in Kerr JW, Ganderton MA (eds): Proc. XI International Congress of Allergology and Clinical Immunology. London and Basingstoke, The Macmillan Press Ltd 1983, pp 153-158

28. Reinhardt MC: Food allergy: pathogenesis, manifestations, diagnosis, and management, in Businco L (ed): Advances in Pediatric Allergy, Excerpta Medica, Amsterdam, pp 155-191, 1983

29. Gruskay FL, Cooke RE: The gastrointestinal absorption of unaltered protein in normal infants and in infants recovering from diarrhea. Pediatrics 16:763-769, 1955

30. Rothberg RM: Immunoglobulin and specific antibody synthesis during the first weeks of life of premature infants. J Pediatr 75:391-399, 1969

31. Hanson LA, Ahlstedt S, Carlsson B, Fällström SP, Kaijser B, Lindblad BS, Sohl Akerlund A, Svanborg Edén C: New knowledge in human milk immunoglobulin. Acta Paediatr Scand 67:577-582, 1978

32. Selner JC, Merrill MA, Claman HN: Salivary immunoglobulin and albumin: development during the newborn period. J Pediatr 72:685-689, 1968

33. Hanson LA, Carlsson B, Fällström SP, Mellander L, Porras O, Söderström T: Food and immunological development. Acta Paediatr Scand suppl 299:38-42, 1982

34. Eisen HN: Immunology, 2nd ed. Harper and Row, Publishers, Hagerstown, 1980

35. Good RA, Cunningham-Rundles C: Immunoglobulin A deficiency, in Bergsma D (ed) Birth Defect Compendium, 2nd ed. Alan R. Liss, Inc, New York, p 580, 1979

36. Cunningham-Rundles C, Brandeis WE, Good RA, Day NK: Milk precipitins, circulating immune complexes, and IgA deficiency. Proc Natl Acad Sci 75:3387-3389, 1978

37. Luzi G, Businco L, Aiuti F: Primary immunodeficiency syndromes in Italy: a report of the national register in children and adults. Clin Immunol Immunopathol (in press) 
38. Matthew DJ, Taylor B, Norman PA, Turner MW, Soothill JF: Prevention of eczema. Lancet I:321-324, 1977

39. Smith JM: Epidemiology and natural history of asthma, allergic rhinitis, and atopic dermatitis (eczema), in Middleton E, Reed CE, Ellis EF (eds): Allergy, Principles and Practice, 2nd ed. The C.V. Mosby and Co, Saint Louis, pp 771-803, 1983

40. Businco L, Marchetti F, Pellegrini G, Cantani A, Perlini R: Prevention of atopic disease in at risk newborns by prolonged breast-feeding. Ann Allergy 51:296-299, 1983

41. Soothill JF, Stokes CR, Turner MW, Norman AP, Taylor B: Predisposing factors and the development of reaginic allergy in infancy. Clin Allergy 6:305-319, 1976

42. Björkstén B, Suoniemi I: Dependence of immediate hypersensitivity on the month of birth. Clin Allergy 6:165-171, 1976

43. Morrison Smith J, Springett VH: Atopic disease and month of birth. Clin Allergy 9:153-157, 1979

44. Roberts J, Carron R: Pollinose précoce des natifs du Taureau. Rev Franç Allergol Immunol 19:152-155, 1979

45. Businco L, Rossi P: Immunodeficienza ed allergia. Atti XV Congr Naz Soc Ital Allergologia e Immunologia Clinica, Roma 30 ott-1 nov 1981

46. Juto P, Möller C, Engberg S, Björkstén B: Influence of type of feeding on lymphocyte function and development of infantile allergy. Clin Allergy 12:409-416, 1982

47. Strannegård $\mathrm{O}$, Strannegård IL: T lymphocyte numbers and function in human IgE-mediated allergy. Immunol Rev 41:149-170, 1978

48. Eastham EJ, Lichauco T, Grady MI, Walker WA: Antigenicity of infant formulas: Role of immature intestine on protein permeability. J Pediatr 93:561-564, 1978

49. Michel FB, Bousquet J, Greillier P, Robinet-Lévy M, Coulomb Y: Comparison of cord blood immunoglobulin $\mathrm{E}$ concentration and maternal allergy for the prediction of atopic diseases in infancy. J Allergy Clin Immunol 65:422-430, 1980

50. Ratner B: A possible causal-factor of food allergy in certain infants. Am J Dis Child 36:277-288, 1928

51. Miller DL, Hirvonen T, Gitlin D: Synthesis of IgE by the human conceptus. J Allergy Clin Immunol 52:182-188, 1973

52. Singer AD, Hobel CJ, Heiner DC: Evidence for secretory IgA and IgE in utero (abstract). J Allergy Clin Immunol 53:94, 1974

53. Frick LO, German DF, Mills J: Development of allergy in children. I. Association with virus infections. J Allergy Clin Immunol 63:228-241, 1979

54. Businco L, Businco E: Atopia nella prima infanzia. Atti Meeting Internaz. Immunologia ed Allergologia Pediatrica. Firenze, maggio 1981

55. Lyon GM: Allergy in an infant of three weeks. Am J Dis Child 36:1012-1016, 1928

56. London RL, Glaser J: The cutaneous reactions to egg white. Pediatrics 24:1009-1015, 1959

57. Vaughan VC III: Prophylaxis of allergic disease in children. Ann Allergy 22:468-474, 1964

58. Hamburger RN: Discussion. Businco L (ed), Advances in Pediatric Allergy. Excerpta Medica, Amsterdam, pp 115-116, 1983

59. Johnstone DE, Dutton AM: Dietary prophylaxis of allergic diseases in children. N Engl J Med 274:715-719, 1966

60. Shannon WR: Eczema in breast-fed infants as a result of sensitization to foods in the mother's dietary. Am J Dis Child 23:392-405, 1922

61. Matsumura T, Kuroume T, Oguri M, Iwasaki I, Kanbe Y, Yamada T, Kawabe S, Negishi $\mathrm{K}$ : Egg sensitivity and eczematous manifestations in breast-fed newborns with particular reference to intrauterine sensitization. Ann Allergy 35:221-229, 1975

62. Wittig HJ, McLaughlin ET, Leifer KL, Belliot JD: Risk factors for the development of allergic disease: Analysis of 2190 patient records. Ann Allergy 41:84-88, 1978

63. Zetterstrom O, Osterman K, Machado L, Johansson SGO: Another smoking hazard: raised serum $\operatorname{IgE}$ concentration and increased risk of occupational allergy. Br Med J 283:1215-1217, 1981

64. Kjellman NIM: Effect of parental smoking on IgE levels in children. Lancet I:993-994, 1981 
65. Fergusson DM, Horwood LJ, Shannon FT: Parental smoking and respiratory illness in infancy. Arch Dis Child 55:358-361, 1980

66. Businco L, Cantani A: Asma bronchiale infantile: nuovi orientamenti sull'etiopatogenesi e sulla terapia. Aggiorn Med 2:167-176, 1982

67. Kark JD, Lebiush M, Rannon L: Cigarette smoking as a risk factor for epidemic $A\left(\mathrm{H}_{1} \mathrm{~N}_{1}\right)$ influenza in young men. N Engl J Med 307:1042-1046, 1982

68. Colley JRT: Respiratory symptoms in children and parental smoking and phlegm production. Br Med J II:201-204, 1974

69. Platts-Mills TAE, Tovey ER, Mitchell EB, Moszoro H, Nock P, Wilkins SR: Reduction of bronchial hyperreactivity during prolonged allergen avoidance. Lancet II:675-678, 1982

70. Altounyan REC: Review of the clinical activity and modes of action of sodium cromoglycate, in: Pepys J, Edwards AM (eds): The Mast Cell-Its Role in Health and Disease. Pitman Medical Publishing Co, Ltd, Tunbridge Wells, pp 199-216, 1979

71. Bahna SL, Horwitz CA, Fiala M, Heiner DC: Changes in serum IgE and IgM levels in heterophil-antibody positive infectious mononucleosis (HA + IM) (abstract). Pediatr Res 11:484, 1977

72. Perelmutter L, Phipps P, Potvin L: Viral infections and IgE levels. Ann Allergy 41:158-159, 1978

73. Welliver RC, Kaul TN, Ogra PL: The appearance of cell-bound IgE in respiratory-tract epithelium after respiratory-syncytial-virus infection. N Engl J Med 303:1198-1202, 1980

74. Welliver RC, Wong DT, Sun M, Middleton E Jr, Vaughan RS, Ogra PL: The development of respiratory syncytial virus-specific $\operatorname{IgE}$ and the release of histamine in nasopharyngeal secretions after infection. N Engl J Med 305:841-846, 1981

75. Szentivanyi A: The $\beta$-adrenergic theory of the atopic abnormality in bronchial asthma. J Allergy Clin Immunol 42:203-232, 1968

76. Welliver RC, Kaul A, Ogra PL: Cell-mediated immune response to respiratory-syncytialvirus infection: relationship to the development of reactive airway disease. J Pediatr 94:370-375, 1979

77. Ward PA, Dvorak HF, Cohen S, Yoshida T, Data R, Selvaggio SS: Chemotaxis of basophils by lymphocyte-dependent and lymphocyte-independent mechanisms. J Immunol 114:1523-1531, 1975

78. Ida S, Hooks JJ, Siraganian RP, Notkins AL: Enhancement of IgE-mediated release from human basophils by viruses: role of interferon. J Exp Med 145:892-906, 1977

79. Wittig HJ, Cranford NJ, Glaser J: The relationship between bronchiolitis and childhood asthma. A follow-up study of 100 cases of bronchiolitis in infancy. J Allergy 30:19-23, 1959

80. Businco L, Ruberto U, Businco E: Contributo allo studio dei rapporti fra bronchiolite ed asma nel bambino. Riv Clin Ped 81:946-948, 1968

81. Lev R, Orlic D: Uptake of proteins in swallowed amniotic fluid by monkey fetal intestine in utero. Gastroenterology 65:60-68, 1973

82. Moxey PC, Trier JS: Structural features of the mucosa of human fetal small intestine. Gastroenterology 68:1002-1009, 1975

83. Hanson LA, Winberg J: Breast milk and defence against infection in the newborn. Arch Dis Child 47:845-847, 1972

84. Reddy V, Bhaskaran C, Raghuramulu N, Jagadeeson V: Antimicrobial factors in human milk. Acta Paediatr Scand 66:229-232, 1977

85. Kraehenbuhl JP, Bron C, Sordat B: Transfer of humoral secretory and cellular immunity from mother to offspring, in: Grundmann E (ed): Perinatal Pathology. Springer-Verlag Berlin, Heidelberg, New York, pp 105-157, 1979

86. Firer MA, Hosking CS, Hill DJ: Effect of antigen load on development of milk antibodies in infants allergic to milk. Br Med J 283:693-696, 1981

87. Jarrett EE, Hall E: Selective suppression of $\operatorname{IgE}$ antibody responsiveness by maternal influence. Nature 280:145-147, 1979

88. Roberts SA, Soothill JF: Provocation of allergic response by supplementary feeds of cow's milk. Arch Dis Child 57:127-130, 1982 
89. Roberts SA, Reinhardt MC, Paganelli R, Levinsky RJ: Specific antigen exclusion and nonspecific facilitation of antigen entry across the gut in rats allergic to food proteins. Clin Exp Immunol 45:131-136, 1981

90. Chandra RK: Prospective studies of the effect of breast feeding on incidence of infection and allergy. Acta Paediatr Scand 68:691-694, 1979

91. Saarinen UM, Kajosaari M, Backman A, Siimes MA: Prolonged breast-feeding as a prophylaxis for atopic disease. Lancet II:163-166, 1979

92. Hamburger R: Prophylaxis of atopic asthma. Atti Convegno Internaz. L'evoluzione naturale dell'asma bronchiale dall'infanzia all'età adulta. Salsomaggiore, Giugno 1979

93. Kaufman HS, Frick OL: Prevention of asthma. Clin Allergy 11:549-553, 1981

94. Grulee CG, Sanford HN: The influence of breast and artificial feeding on infantile eczema. J Pediatr 9:223-225, 1936

95. Halpern SR, Sellars WA, Johnson RB, Anderson DW, Saperstein S, Reisch JS: Development of childhood allergy in infants fed breast, soy or cow's milk. J Allergy Clin Immunol 51:139-151, 1973

96. Blair H: Natural history of childhood asthma. Arch Dis Child 52:613-619, 1977

97. Kramer MS, Moroz B: Do breast-feeding and delayed introduction of solid foods protect against subsequent eczema? J Pediatr 98:546-550, 1981

98. Gordon RR, Ward AM, Noble DA, Allen R: Immunoglobulin E and the eczema-asthma syndrome in early childhood. Lancet I:72-74, 1982

99. Businco L, Rossi P: Recenti acquisizioni sui fattori anti-infettivi del latte umano. Immunol Ped 1:4-8, 1980

100. Heird WC, Hansen IH: Effect of colostrum on growth of intestinal mucosa (abstract). Pediatr Res 11:406, 1977

101. Bullen CL, Tearle PV, Stewart MG: The effect of "humanized" milks and supplemental breast feeding on the faecal flora of infants. J Med Microbiol 10:403-413, 1977

102. Simhon A, Douglas JR, Drasan BS, Soothill JF: Effect of feeding on infants' faecal flora. Arch Dis Child 57:54-58, 1982

103. Pittard WB III, Bill K: Immunoregulation by breast milk cells. Cell Immunol 42:437-441, 1979

104. Juto P: Immune responses, type of feeding and atopic allergy in infants. A prospective study. Umeå University Medical Dissertations. New Series, 57, 1980

105. Croner S, Kjellman NIM, Eriksson B, Roth A: IgE screening in 1701 newborns and the development of atopic disease during infancy. Arch Dis Child 57:364-370, 1982

106. Björkstén B, Juto P: Allergy and cell-mediated immunity in infants, in Businco L (ed): Advances in Pediatric Allergy. Excerpta Medica, Amsterdam, pp 19-28, 1983

107. Francis DEM: Dietary management. Proceedings of the 1st Food Allergy Workshop. Medical Education Services Limited, Oxford, pp 85-94, 1980 